\title{
Pollution as a Paradigm: Property, Dignity, and Absorption in Poth and Tezuka
}

\author{
Sonja Schillings \\ Germany
}

\begin{abstract}
Pollution challenges the fundamental structural premises of contemporary state institutions such as the law. These institutions, this article suggests, are based on the premise of human exceptionalism via the construction of a humannature divide. This divide only allows one point of connection between human and nature: the human ability to absorb nature as property. Such metaphorical understandings of absorption become a problem as soon as the physical human body is faced with a situation in which we constantly absorb pollution (e.g. nitrogen oxides, microplastic, ionizing radiation, but also other life forms such as airborne viruses). As a result, contemporary institutions are ill-equipped to deal with pollution as a central element of the contemporary human condition.

This article suggests that comics are a model for rethinking these categorical issues productively and sustainably. By using visual elements, comics have already been able to reframe and recontextualize categorical premises such as the human-nature divide that otherwise tend to be reproduced in critical theory and the law. To make this point for the potential of a new categorical language that centrally draws on visual elements in text, the article uses two central examples from Japan and Germany: Osamu Tezuka's story "Space Snow Leopard" from the Astro Boy series, and Chlodwig Poth's short comic "Jörg the Limelight Hog."
\end{abstract}

Keywords: Pollution; human-nature divide; Osamu Tezuka; Chlodwig Poth; human dignity; property.

\section{Introduction}

This article discusses institutional fantasies that line up around the notion of a human-nature divide (i.e., the idea of an inherent human difference from, and superiority to, all other life forms). The associated fantasy that interests me here is the idea of human immunity to whatever happens in "nature." This notion of "insular individuality"1 and its environmental detachment is particularly problematic when facing the issue of environmental pollution.

The term "pollution" itself is derogatory. It implies that something pure and whole (in this case, the human body) is soiled by some alien contamination. When I speak of pollution in this article, I use the term neutrally. I mean that something (e.g., not only nitrogen oxides, microplastic, and ionizing radiation but also other life forms, such as airborne viruses) is absorbed by the human body and thereby causes harm to the organism. But even though there is harm and there is cause for (re)action, there is no lost purity.

In putting it this way, the article draws on a growing body of interdisciplinary research that not only claims the impossibility of a dichotomist view of pollution in the spirit of the human-nature divide but also insists on humans' inherent organic entanglement with other life forms. ${ }^{2}$ Nevertheless, the dichotomist, insular view is still deeply engrained in the structure of contemporary categorical thought and the governing principles of state institutions, such as the law. This is a problem insofar as it leaves institutions ill-equipped to address the harm that may result from precisely such entanglements of human bodies and their "natural" environment.

\footnotetext{
${ }^{1}$ Gilbert, "Symbiotic Way of Life," 326.

${ }^{2}$ See, e.g., Griffiths, "Queer Theory for Lichens," 37-38.
}

Except where otherwise noted, content in this journal is licensed under a Creative Commons Attribution 4.0 International Licence. As an open access journal, articles are free to use with proper attribution. ISSN: 2652-4074 (Online) 
It seems necessary to build bridges between the paradigms of "insular" institutional discourse on the one hand and the emerging paradigm of symbiotic human entanglement on the other. In this article, I suggest considering comics' potential to reframe the premises of philosophical and theoretical language to better build such bridges and to bring such mutually exclusive paradigms into constructive conversation with each other.

In this article, I first use the structural model of a comic by the German satirist Chlodwig Poth to discuss the human-nature divide as a philosophical backdrop to most institutional approaches in industrialized countries, as well as to summarize and highlight the limits of these approaches when it comes to pollution. In a second step, I will offer a close reading of a text taken from Osamu Tezuka's classic manga series Astro Boy to suggest that comics, in particular, may serve as a surprisingly successful formal model to radically rework central paradigms that govern institutional responses to pollution from within the reservoir of institutional traditions.

My examples are held together by their shared focus on radioactive pollution, a form of pollution that has immeasurably affected philosophy and global institutional history. This effect, interestingly, is largely informed by the aesthetic history of nuclear energy. Iconic images of the mushroom cloud have not only shaped perceptions of nuclear energy but also focused attention on the invisible effects of nuclear reactions (i.e., ionizing radiation).

The post-1945 rise of the atomic age coincided with both the rise of still and animated images as a unifying cultural technique across the globe and, not least, the rise of comics as a popular mass medium. ${ }^{3}$ The examples used here are therefore taken from a rich global reservoir of sources and should not be considered unique in their thematic and formal preoccupations.

The article itself is entirely without images. Awkward as that is, it is ultimately part of the point. As a twenty-first-century reader with access to the Internet, you already know the images around which this text revolves. Picture these scenarios: whole forests burning brightly against a black night sky; a city flooded by dirty gray water; industrial chimneys smoking against a dusty red sky; and waste dumps extending as far as the horizon.

Picture the mushroom cloud.

Familiar stock images such as these form the baseline of this article; with that in mind, let me tell you a story that will lead us straight to the problem of the human-nature divide. The story is the plot of a ten-panel comic published in 1982 by Chlodwig Poth, a German cartoonist and social satirist. Loosely translated from German, the title is "Jörg, the Limelight Hog."

The story is set in a private living room; seven adult friends are grouped around a table. They drink and smoke and have been at it for a while. The cat has long gone to sleep. Meanwhile, the partygoers talk about the end of the world. They discuss current affairs, especially the neutron bomb that had recently been made operable as a conventional weapon. They talk about geopolitics based on ever-escalating dynamics of provocation. They agree that humankind is doomed because the development of ever more potent nuclear weapons will inevitably lead to nuclear war. "We don't even need the big bang," one of them summarizes, "We are already well ahead, destroying ourselves by making the planet uninhabitable." Another adds, "It'll be like the lemmings. Life becomes ever more unbearable, and then we all just march off to haul ourselves over the cliff." "Exactly," a third concludes, "And the cliff is the big atomic bang."

They agree so much that you, while you read, barely take the time to identify who's talking; you barely take note of the characters beneath the barrage of interlocking speech bubbles. But there is something to see at the table. One of the characters says nothing, yet his face reflects increasing alarm. He goes on to write something on a piece of paper; he plays with a pill, then he swallows it. ${ }^{5}$ In the next panel, he jumps up and grabs his throat. He groans, twists, goes down. He is dead. The shocked partygoers find his note on the table: "I am, and will always remain, an individualist. I could not bear mass death. Yours, Jörg."

Personally, I find this hilarious.

Even if you do not see the humor, you may appreciate the mechanics of the joke. Jörg's suicide is surprising because even though the conversation revolves around the certainty of doom and death, it surely was not meant that literally. By making the connection between informed analysis and suicide so immediately, Jörg's dramatic intervention illuminates the talkers' gossipy detachment from their topic. For all of their penetrating analysis of geopolitical escalation, we do not see any of the other

\footnotetext{
${ }^{3}$ See, e.g., Rhoades, Complete History of American Comic Books.

${ }^{4}$ Poth, "Jörg, der Effekthascher," 154.

${ }^{5}$ Poth, "Jörg, der Effekthascher," 154-55.

" Poth, "Jörg, der Effekthascher," 157.
} 
characters draw an existential conclusion from the human-made catastrophe they predict. They are anxious but ultimately cavalier.

Jörg does something with the information he receives, but his suicide looks like a limelight-hogging pun because he does not actually offer a different perspective. Instead, Poth connects the two levels of the comic-the conversation and Jörg's preparations of suicide - by identifying a shared source of detachment, namely reading.

It is quite evident that the partygoers take their information from newspapers and analyses of current events. As for Jörg, he is a reader of history. There is a rather specifically German subtext to his suicide that helps tease out his stance on readership. Jörg happens to carry a cyanide pill around, a precaution made famous by high-ranking Nazis, like Erwin Rommel, who sought to evade capture toward the end of the Second World War. His note, meanwhile, alludes to a cultural memory of the Third Reich in postwar history that was especially formative for the generation depicted here. Jörg "could not bear mass death" because he is an individualist. In the Western German context of the 1980s, the de-individualizing idea of "mass death" was directly informed by the overwhelming cultural presence of the Holocaust's death statistics.

The humanity of the dead is easily lost on those who read death statistics. In anecdotal conversation, historians of genocide frequently describe the effect of reading death statistics as a slow-burning kind of horror: whatever made the people in these statistics human and whatever individuality each of them had become irretrievably lost in the statistically significant multitude. To be sure, massified lives and deaths do not lose humanity to themselves; lives were still lead, no matter how and when death came to them. Jörg's particular dread of mass death, though, is caused by abstracted mediation. Even as Jörg imagines the death of everything, he cannot imagine a situation in which human history will not look back and count the dead.

"I still just can't imagine it," says one of the partygoers about the end of the world. "Of course not, nobody can imagine that," agrees another just as Jörg swallows the pill, ultimately choosing to evade capture in the face of certain doom. ${ }^{7}$

The humor of the comic draws on an often-noted human inability to imagine our individual or collective end. ${ }^{8}$ The recognition of death is never quite translatable into the organization of everyday life. That is not, in and of itself, a problem, much less a problem that I want to disentangle here. The problem that I do want to explore is this: Poth dramatizes a perspective on catastrophe in the 1980s that we still recognize all too well in 2020.

Through the juxtaposition of conversation (words) and suicide preparation (images) in "Jörg, the Limelight Hog," the comic establishes parallel narratives that ultimately crash into each other. What is happening on the level of image massively recontextualizes the conversation, in that it suggests that analysis and suicide are variations of each other. The juxtaposition illuminates that the real issue is not the fact of our future death-individual or collective. The problem is that we (speaking, for the moment, for the industrialized West) have a strong tendency to conflate present global problems (Militarization! Deforestation! Poisoned oceans! Climate Change!), with the very idea of death as an all-encompassing, existential—but always inherently future - fact. After all, it has not come; we are not dead ourselves yet; we are simply, inevitably, marching toward the cliff.

Such conflation makes for a decent novella but not for a decent philosophical or political vision of dealing with the world we actually inhabit. Our daunting global problems - chiefly pollution — are not best described as a poetically inevitable conclusion of life on earth in the future. Instead, these problems constitute the condition of life on earth in the present. To conflate even the most basic recognition of the conditions of the present with the idea of total future death means not to deal with it at all.

"This picture shows the detonation of an atomic bomb."

Why is pollution in general (which makes the world uninhabitable), and nuclear energy in particular (the big bang), so difficult to grasp as a problem of the present and, therefore, as a social factor in our lives? I suggest that the human-nature divide, along with fantasies of immunity to pollution, has a great role to play here. But then, how to avoid the quandary of appropriate language faced by the characters in "Jörg" and how to think about such challenges differently than they do? This is where we arrive at a discussion of Astro Boy, where we actually find a starting point for sustainable new approaches.

\section{The Cold War and the Activism-Apathy Cycle}

When the first nuclear explosion on earth was unleashed during the Trinity Test on July 16, 1945, the human ability to push a button and transform the planet to its core was there for all the world to see: behold, the mushroom cloud. But it soon turned

\footnotetext{
${ }^{7}$ Poth, "Jörg, der Effekthascher," 155.

${ }^{8}$ See, e.g., Langton, "What's the Point of Immortality?"
} 
out that the atomic bomb constituted not only a singular awful moment. It also constituted an event with far-reaching and uncontrollable consequences, as the mushroom cloud creates clouds of radiation in its wake - a phenomenon first widely noted in the aftermath of the attacks on Hiroshima and Nagasaki (August 6 and 9, 1945, respectively).

Despite a new geopolitical emphasis on containment and international cooperation after the attacks on Hiroshima and Nagasaki, the superpowers' treatment of the bomb remained integrated into traditional frameworks of warfare. ${ }^{9}$ Poth's characters were not too far off in their assessment here: the United States and the Soviet Union doubled down, and at the same time systematically played down effects of atomic bombs, including the effects of ionizing radiation. Access to nuclear weapons did not remain a privilege of superpowers, either. At the time of writing this article, more than 1500 atomic tests had been conducted on earth, each of them releasing ionizing radiation. This is on top of the radioactivity unleashed by malfunctioning nuclear reactors and the long-term poisonous effects of nuclear waste in the ground and water. ${ }^{10}$ Concentrated clouds of ionizing radiation have already substantially changed the living conditions on the planet. That much has been known for decades.

In response to these first dawning realizations in the late 1940s, a kind of consciousness formed during the Cold War that the cultural historian Paul Boyer described around the same time that Poth published "Jörg." In 1985, Boyer noted that U.S. society (the focus of his study) exhibited regular "cycles of activism and apathy" when it came to a reckoning with the effects of nuclear power on human life. ${ }^{11}$ Boyer showed that in every "activist" cycle since 1945, nearly identical lines of philosophical, theological, activist, and economic arguments were raised to problematize nuclear energy (Poth's partygoers are an excellent example of these typical lines of analysis). Once these near-identical arguments and concerns have been voiced and discussed, they deflate again and are replaced with leaden apathy. Eventually, some catastrophe or crisis occurs, and the cycle repeats.

In her recent book about the meltdown of the Chernobyl nuclear power plant on April 26, 1986, environmental historian Kate Brown provided a partial explanation for the cycles of activism and apathy that Boyer described and Poth dramatized. She kicked off her book with an anecdote from Kyiv, the Ukrainian capital, during the immediate aftermath of the catastrophe. Kyiv is geographically close to Chernobyl, and the entire region was part of the Soviet Union in 1986. Brown wrote:

\begin{abstract}
The festivities went ahead as planned in Kyiv on orders from Moscow. [...] The newsreels of the May holiday did not record the actions of two and a half million lungs, inhaling and exhaling, working like a giant organic filter. Half of the radioactive substances Kyvians inhaled their bodies retained. Plants and trees in the lovely, tree-lined city scrubbed the air of ionizing radiation. When the leaves fell later that autumn, they needed to be treated as radioactive waste. Such is nature's stunning efficiency at absorbing bursts of radioactivity after a nuclear explosion. ${ }^{12}$
\end{abstract}

This paragraph includes two notable points. First, Brown emphasized that radiation is not something that living bodies-be those the bodies of trees, animals, or humans - are entirely unequipped to deal with. We come prepared, to a degree: life on earth exhibits a "stunning efficiency" at absorbing and filtering ionizing radiation. Life goes on, though at a great cost to the individual organism and the entire web of lives affected by the long-term effects of ionizing radiation on the soil.

Second, other than an explosion, which is loud and bright and creates an unambiguous before-after caesura, ionizing radiation is invisible and unfolds its destructive power over the course of many decades. In other words, institutions can explain away or outright ignore the effects of ionizing radiation if they choose to do so. In accord with a wealth of other critical work on the production and treatment of data in international scientific work on ionizing radiation, ${ }^{13}$ Brown's account unpacked a global history of "not dealing with it."

Brown suggested that Boyer's cycles of activism and apathy are directly bound up with both a struggle over access to information and a global institutional history of politically motivated misinformation. Poth's talkative partygoers cannot react adequately to the threats they describe: even though the fact of lethal radioactive pollution is known and images of the bomb are nothing less than iconic today, there is a missing link between these phenomena and our lives.

This affects the meaning of images such as the mushroom cloud: even though they inspire anxiety and unease, they primarily constitute aesthetic encounters. One may relate to them affectively but not necessarily politically or, importantly, legallywhich is particularly surprising, since much of social activism today refers to reforms in international law that came after the Second World War.

\footnotetext{
${ }^{9}$ Wormouth, To Chain the Dog of War, 273.

${ }^{10}$ See Jacobs, "Nuclear Conquistadors," 157-77.

${ }^{11}$ Boyer, By the Bomb's Early Light, 352.

${ }^{12}$ Brown, Manual for Survival, 6.

${ }^{13}$ See, e.g., Guleria, "Harmful Effects of Ionizing Radiation”; Krupar, Hot Spotter's Report.
} 
It follows that when images such as the mushroom cloud do take a political turn in our own present, one can expect them to be used metaphorically. Consider the following example. The meme generator imgflip.com features a template titled "Atomic Bomb Template (also called: atomic bomb mushroom)." On the website, each template is accompanied by a revolving set of three "featured memes" that illustrate what others have done with the specific template. On July 8, 2020, the image of the atomic bomb's detonation was combined with the following slogans: "There goes my Samsung Galaxy S7," "Another Deep State Coup," and "Half- Lives Matter."

\section{The Human-Nature Divide: Human Exceptionalism and Social Justice}

As you pause to consider what to think of these memes (the last meme being a jab at the Black Lives Matter movement that roared back to national significance in the aftermath of George Floyd's killing by a police officer in the United States at the same time that I accessed the memes), allow me to distract you by talking about human exceptionalism for a bit.

Today, the very use of the term "human exceptionalism" announces that a researcher rejects the idea of a unique human place among the life forms. People who do defend (or tacitly accept) the idea of human exceptionalism tend not to talk about it as human exceptionalism. The preferred term is human dignity, understood in the sense of a unique human essence that sets us apart from all other life. Various traditional positions on human dignity suggest, for example, that humans are the divinely chosen species and that humans alone have consciousness and agency, that humans alone advance by using technological progress, and that humans alone can own property. ${ }^{14}$ This idea has many manifestations because it is old, and people have tried to substantiate it in all sorts of ways. Cicero, for example, cited the upright walk as an indicator of the special place of humanity in the world, ${ }^{15}$ thus demonstrating his unfamiliarity with penguins.

What all these different exceptionalist traditions of thought have in common is that they speak of the special place of the human as a privilege (one that comes, naturally, with the grave responsibilities of a heavy crown). The essence of human exceptionalism is a fundamental distinction between active, enlightened Humans and passive, obtuse Others, or, put more traditionally yet, between humans and nature. The human-nature divide informs all of these heterogeneous dignity traditions of thought. It is quite secondary which kind of human essence you determine or where in the human you locate it. Within discourses of human exceptionalism, it is instead central to argue how exactly "nature" collectively relates to human uniqueness. But just as human exceptionalism is not actually about the study of human properties, the human-nature divide is not actually about species difference. Humans have frequently found themselves on the nature side of the human-nature divide. In European-led modernity, for example, racializing international law treated indigenous populations as fragments of an "empty territory." 16 Systems of chattel slavery explicitly cast enslaved humans as livestock. ${ }^{17}$ Such treatment was not restricted to the treatment of BIPOC ${ }^{18}$ populations, either; white Europeans of "lower" classes and social outcasts within Europe were frequently cast as animals along similar lines. ${ }^{19}$ The implications of these colonialist traditions of human exceptionalism were most infamously exemplified by the Third Reich's designation of Jews as "vermin" or "viruses" as a justification of genocide. ${ }^{20}$

The Universal Declaration of Human Rights of 1948 began with the claim that the "recognition of the inherent dignity and of the equal and inalienable rights of all members of the human family is the foundation of freedom, justice and peace in the world" (emphasis mine). ${ }^{21}$ By linking the foundation of peace to the institutional recognition of human dignity, documents such as the Universal Declaration markedly deviate from colonialist theories of peace, which mainly associated a state of peace with the existence of trade and, therefore, on the structural centrality of property. ${ }^{22}$

This is not an accident, and the tradition of property turns out to be central to discussing pollution. That is because modern Western notions of human dignity rest on a central metaphor of bodily absorption: the human is able to metaphorically expand his ${ }^{23}$ body through property so that he can no longer be separated from everything he owns and represents. John Locke's

\footnotetext{
${ }^{14}$ For some excellent overviews of these and other positions, see, e.g., Düwell, Cambridge Handbook of Human Dignity; McCrudden, Understanding Human Dignity; Wetz, Texte zur Menschenwürde.

${ }^{15}$ See Wetz, Texte zur Menschenwürde, 33.

${ }^{16}$ See, e.g., Washburn, Red Man's Land; Fisch, Die europäische Expansion und das Völkerrecht.

${ }^{17}$ Kuri, “Animals, Slaves, and Corporations," 1069-90.

${ }^{18}$ BIPOC stands for "Black, Indigenous, People of Color." It is a useful term for the contexts discussed here, since it acknowledges substantial differences between the forms of systemic discrimination experienced by Black and Indigenous populations during colonialism.

${ }^{19}$ See, e.g., Olson, Criminals as Animals.

${ }^{20}$ Harrison, Understanding Political Ideas and Movements, 263.

${ }^{21}$ UN General Assembly, Universal Declaration of Human Rights, Preamble.

${ }^{22}$ Kant, "Perpetual Peace."

${ }^{23}$ The representative individual in Locke is by definition male, and also expands his body to encompass the represented members of his family.
} 
influential theories of institutional statehood, for example, are squarely based on merging the double sense of the word "property," which may designate features of both the body and owned objects, ${ }^{24}$ with the result that the human being in the liberal tradition is ultimately not conceived to be a body but to own a body. ${ }^{25}$ Such a strictly metaphorical treatment of both the body itself and bodily absorption as the generation of property renders property as the axis that relates human to and separates human from nature. Contemporary institutional models overwhelmingly continue to revolve around property in precisely this sense.

For example, let us take a brief look at the Convention on Supplementary Compensation for Nuclear Damage (CSC) under the auspices of the International Atomic Energy Agency. This convention regulates what happens after a nuclear accident occurs and acknowledges both grave health effects for humans as well as grave (and somewhat unpredictable) effects for an "impaired environment." 26 It is a typical document insofar as that nuclear treatises and conventions are often based in liability law. The focus on property and economic losses is consistently defining throughout the document, and it is the threat to property that informs how the harm to human bodies and an "impaired environment" is understood. ${ }^{27}$

The CSC thus performs an almost impossible act of translation. The physically transformative effect of pollution by ionizing radiation (on us, on our environment, unevenly, and for generations to come) can be expressed only within the limits of a language that mediates a single, isolated encounter: humans and their property versus the non-human force of ionizing radiation. In the end, we are not talking about bodies absorbing radiation but about economies absorbing losses. That may sound like a slogan, but the point is rather serious. Legal institutions cannot operate outside an institutional framework that relies on a strictly metaphorical idea of bodily absorption. To the cloud of radiation that occasions the existence of the CSC, the human body is an organic filter just like any other. But lawmakers have to coherently and appropriately deal with the problem of ionizing radiation within the law (as they certainly try to do in the case of the CSC). The lawmakers' and legal scholars' task becomes making the conditions and effects of non-metaphorical absorption legible within a framework that revolves around a foundational commitment to metaphorical absorption (i.e., to property in the liberal tradition). The balancing act is very nearly category-exploding.

In other words - and do go ahead and picture the other images, the burning forests, the polluted sea, the smog in the sky-the basic institutional distinction between human and nature actively hinders a profound legal acknowledgement of nonmetaphorical pollution as a core condition of contemporary life. But at least we can see the human-nature divide as a problematic undercurrent and critique that, right? Certainly we can. But like the law, theory and criticism run into structural difficulties that bring us uncomfortably close to the issue of evasive (and therefore inconsequential) analysis that Poth satirized in "Jörg, the Limelight Hog."

The human-nature divide has been taken to task particularly profoundly since the late 1940s when the atomic bomb and the Holocaust together raised awareness of humans' existential exposure to institutional practices designed to "identify" entire human populations as humanity-polluting fragments of nature. However, human rights law-which most of these critical interventions refer to - is itself explicitly human exceptionalist. ${ }^{28}$ Its point is to forestall the discriminatory (and, at worst, genocidal) exclusion of certain human populations from the human family. Accordingly, anti-discriminatory arguments (e.g., by feminist and BIPOC voices) tend not to criticize human exceptionalism itself but an inconsistent application of human exceptionalism. ${ }^{29}$ There is, indeed, a marked reluctance in this tradition to consider humans an element of nature because of a justified concern that such an acknowledgement might play into the hands of political actors who would use it to double down on the idea that certain humans are subhuman. ${ }^{30}$

Not only legal but also political discourses of property and social justice thus draw on human exceptionalism quite directly, and it is not surprising that such a strong bias would show ripple effects even in arguments that both explicitly acknowledge the special challenges of pollution and/or seek to challenge the notion of essentialist human supremacy. For example, consider the book The Posthuman by the philosopher and theorist Rosi Braidotti, who labels herself an anti-Humanist. She evoked the

\footnotetext{
${ }^{24}$ Locke, "Second Treatise of Government," 287-88.

${ }^{25}$ Esposito, Person und menschliches Leben, 46.

${ }^{26}$ Convention on Supplementary Compensation for Nuclear Damage, 3.

${ }^{27}$ See Heffron, "Global Nuclear Liability Regime," 1-10.

${ }^{28}$ Geldon, World Made New, 112.

${ }^{29}$ See, e.g., Mills, "Racial Liberalism," 1380-97.

${ }^{30}$ I have come across a rather vivid anecdotal example of the dynamic that ensues when one attempts to consider the greater structural issues of the human-nature divide without factoring in the specific investment of social justice movements in the concept of human dignity (and thus the idea of a shared human essence that requires the equal treatment of all members of society, including those who are structurally discriminated against). The example comes from a popular advice column; it discusses the case of a white vegan who compares the choice to eat vegan with the struggles of the civil rights movement, thus appalling the Black mother of her boyfriend. Lavery, "Dear Prudence."
} 
"Vitruvian Man" as a symbolic figure that stands in for core Humanist ideals-Humanist meaning, in her case, (re)productive of the exceptionalist human-nature divide. She wrote: "Central to this universalistic posture and its binary logic is the notion of 'difference' as pejoration. Subjectivity is equated with consciousness, universal rationality, and self-regulating ethical behavior [in Humanism], whereas Otherness is defined as its negative and speculative counterpart." 31 So far, so familiar.

Braidotti then went on to develop her own approach as a counterposition to Vitruvian Humanism, which she characterized as a position in defense of exclusionary privilege. Yet a counterposition is difficult to formulate without relying heavily on dichotomist logic. Braidotti thus tacitly embraced Humanism's motivating core notion of a divide that creates essentially different and complementary entities. Her Vitruvian Man is a straw figure of privilege that provides her with an Other of her own. If Humanists use nature as a "speculative counterpart" to develop thought about property, ${ }^{32}$ the anti-Humanist Braidotti uses Humanism as a "speculative counterpart" to develop thought about privilege. She essentially structures the voice of her book as a voice of "nature" that stands up against institutionally engrained ideals of "the human." That does much to denaturalize the divide, but it does not actually destabilize it. It just makes use of its structuring logic from the other direction.

If you share my sense of humor, you probably grinning already. After all, I have used Braidotti as a representative straw figure to formulate a counterposition of my own - in an argument, no less, about how the use of straw figures perpetuates dichotomist thinking and how that is unhelpful. It is funny in its own way, and, in a related vein, it is its own variation of Jörg and his friends whose mirroring shortcomings are brought into sharp relief by their shared attempts to come to terms with daunting global problems. Premises and arguments crash and splinter into each other, and attempts to build bridges become either torturous or hilarious.

"Jörg, the Limelight Hog" has helped us along until here. Jörg and his anxious friends runs in parallel tracks that crash into each other to expose a shared logic; by imitating Poth's compositional choices, it was possible to at least outline a basic tension that underlies a wide and sprawling variety of institutional discourses today.

On the one hand, humans are part of a global nature that consistently absorbs pollution and is already collectively affected by the bodily transformations that the absorption of non-metaphorical pollution brings. On the other hand, our lives are regulated by social institutions that consider us as a species detached from the very idea of belonging to the same category as anything else in nature, especially when it comes to the idea of non-metaphorical absorption of nature into the human body.

It is perhaps not surprising that this tension is most readily resolved by displacing the resolution into the future, as these two strands are imagined to crash into each other in an apocalyptic climax that ends both humankind and all categorical problems that plague it.

So, what next? We might like to turn to superhero comics, a famously escapist genre that offers us some relief. It turns out that these comics are actually quite illuminating in their treatment of the twin issues of absorption and pollution in particular. In fact, they are helpful in going further exactly the point at which, in Poth's story, the limelight goes off.

\section{Superhero Comics and the Formal Problem of Bodily Absorption}

Earlier in this article, I spoke of fantasies, and it easily follows that the central fantasy to consider in the context of pollution is that of immunity - the desire to be shielded from harm, to be unaffected, and to live in a bubble of humanness that only property can enter (by invitation, of course, and in well-mannered, controllable ways). It is certainly seductive: Would we prefer that our human lung operates differently from the leaves of the trees because we are the chosen species? Would we prefer that the trees were part of an efficiently absorbing nature but that the Kyvians merely had to sweep up the waste, more out of a sense of order than out of a need for survival? From a human perspective, that is preferable. But it is a fantasy. Because we retain a certain awareness that it is so, we cannot help but toy with the tensions that make the fantasy of immunity operative in the first place.

Just as "Jörg, the Limelight Hog" has helped us triangulate an institutional bias toward the human-nature divide and its theory of absorption through property, there might be a way for us, as a culture steeped in images, to turn to superhero comics that play with the following idea: what if it could work differently? Superhero comics are a great resource to draw on here; after all, the bodily absorption of radioactive material is a traditional feature of the genre.

\footnotetext{
${ }^{31}$ Braidotti, Posthuman, 15 .

32 Braidotti, Posthuman, 15.
} 
The most widespread and typical form of bodily absorption of pollution in superhero comics happens in origin stories. Consider, as one example of many, the character Spiderman who transforms from a human into a superhuman through his exposure to radioactivity through the bite of a radioactive spider. In origin stories such as this, radiation operates like a magic potion that transforms an ordinary person into a superhuman creature. This brand of fantastical thinking typically has only a marginal effect on the narrative universe in which the possibility of such transformation affects few people in isolated incidents. The radioactive spider bites only Peter Parker, then it is done. The event does not indicate a general rule of nature-if it did, Spiderman's narrative universe might look very different indeed.

The enabling (and immediately marginalized) fantasy here is straightforward. You absorb radioactivity into your body. That transforms your body. But you do not get cancer; you get spider senses. You do not get sick; you evolve. This construction is extremely compatible with traditional forms of human exceptionalism, as this tradition widely considers it characteristic for humans to attempt self-cultivation and become more than human. In origin stories, the isolated absorption of radioactivity provides a shortcut to the super-self.

But the absorption theme can also be handled differently - for example, in Superman. Superman is a character that has existed since the 1930s, but in the 1940s, he received an additional characteristic: he could be harmed by kryptonite. Kryptonite became part of the official Superman universe in Superman \#61 (November 1949), and the crystalline substance assumed its famous green hue in $1951 .^{33}$ Exposure to kryptonite is the only thing that can reliably stop Superman.

The characteristics of kryptonite were created during a period in which anything atomic bomb-related could cause massive cultural popularization in the United States. ${ }^{34}$ The fictional mineral was based on an actual mineral that was accidentally created during the Trinity Test. When the bomb was detonated in the desert of New Mexico, the sand became so hot that it melted into green, glassy crystals: trinitite, a pretty but radioactive stone that assumed immediate, though short-lived, pop cultural fame. ${ }^{35}$ The central difference between the real trinitite and the fictional kryptonite is, of course, kryptonite's most defining characteristic: it does not harm humans. The only one affected by its radiation is a super-strong humanoid, Superman. He absorbs it all, and nobody else has to.

This tradition of the Achilles heel is more open to ambiguity and variation than that of the origin story, and a particularly good example is Osamu Tezuka's Astro Boy, widely considered a classic of Japanese manga today. After the flying robot's first appearance in 1952, the adventures of Astro Boy gradually became so popular in Japan that the series sprawled into a franchise including comics, animation series, and video games and came to be internationally famous as well. Astro Boy is particularly renowned for establishing some of the central aesthetic conventions of manga, such as the signature big eyes of the characters and the characteristic cinematic arrangement of panels in action sequences.

The early Astro Boy series (1952-1968) was written by Tezuka alone. The series was structured episodically with self-contained episodes that did not follow a shared arc. The narrative universe of Astro Boy, as well as the properties of individual characters, vary widely from episode to episode. Like the classic American superhero comics, Astro Boy generally operates under an unwavering formula: the world hangs in the balance, the hero steps in, high-paced action sequences ensue, and the day is saved. In contrast to many other superhero comics (including some of the direct inspirations for the series), Astro Boy explored difficult and serious themes, though the heaviness of the themes was cushioned by carnivalesque humor and (in the text discussed here) rigorously happy-ending-invested plotting.

As they feature a hero with a nuclear generator for a heart, Astro Boy stories are almost necessarily rich with references to nuclear energy. For example, the story "Crucifix Island" (1957) featured a robot school located on top of an active uranium mine; 36 "A Day to Remember" (1960) addressed a Japanese holiday that is associated with the remembrance of Hiroshima and Nagasaki; ${ }^{37}$ and "Space Snow Leopard" (1960), the story discussed in greater detail below, broached the theme of radiation poisoning.

In the Japanese original, the character Astro Boy was called Tetsuwan Atomu, or "Mighty Atom." "Mighty" was a direct allusion to Mighty Mouse, an animated Superman parody popular in the 1940s and 1950s. In "Atom," Tezuka more generally picked up on the post-1945 atomic craze in the United States that, among other things, brought the world kryptonite:

\footnotetext{
${ }^{33}$ Other, additional hues of kryptonite, such as gold, white, and red, were added later in the Superman universe. Hammontree, "Adventure Comics," 449.

34 Jennings, "Superman," 800-801.

${ }^{35}$ Giaimo, "Long, Weird Half-Life of Trinitite."

36 Tezuka, "Crucifix Island," 174.

37 Tezuka, "A Day to Remember," 57.
} 
As he recalled much later, he chose the word "Atom" because the Americans were doing nuclear bomb tests and "everyone was talking about 'atoms' then." Like most Japanese who had just survived World War II-during which Hiroshima and Nagasaki were destroyed by American atom bombs - he abhorred nuclear weapons and fervently hoped that peaceful uses of the new technology would emerge. ${ }^{38}$

The character Astro Boy is different from classic American superheroes in several crucial respects. For example, unlike Superman and virtually all other American superheroes, Astro Boy does not have a secret identity. On the page, there is no visual marker to distinguish him from a human boy, ${ }^{39}$ but that does not mean that anyone thinks he is human. Everybody knows that he is a robot. Interestingly, this authorial decision allowed Tezuka to incorporate an immediate dramatization and critique of structural discrimination into the series as early as the $1950 \mathrm{~s}^{40}$ (which stands in contrast to American superhero comics, which, comparatively, have only started to tackle this issue recently). ${ }^{41}$ At the same time, Tezuka did not present a picture of the oppressed versus the oppressors as an issue of good versus evil; as Kieran Tranter pointed out, the ambiguous complexity of all characters renders "the deeper legality of essence" 42 the core problem that Tezuka negotiated in the series.

Considering the aforementioned difficulties in reconciling human dignity-inspired social justice arguments with a paradigm of planetary pollution (precisely because there is a latent reliance on human essence in contemporary social justice arguments based on human rights), it is nothing less than intriguing that Tezuka successfully tackled the issues of pollution and discrimination in the same series against a backdrop of a negotiation of the fantasy of being immune to pollution. An example from this series is therefore especially suited to tie the various strands of this article together.

\section{Pollution as a Paradigm in "Space Snow Leopard"}

For the remainder of this article, I will focus on the Astro Boy story "Space Snow Leopard" (1960). The story begins on a day like any other, when a strange kind of snow begins to fall. The snow turns out to be aliens who prepare for an invasion. This extraterrestrial "amoeba-like" alien life form can shape-shift and manifest both as characters and parts of the setting. We encounter it in the shape of a mad scientist, as his six-legged snow leopard as snow and as slime that recalls ghost story traditions. The aliens "eat pure energy for food" 43 and predatorily absorb the energy of robots and human weapons.

As the snow reaches earth, most robots (including Astro Boy's parents) become dizzy and collapse lifelessly; only the strongest robots are still holding out. Fortunately, the aliens have a weakness. They can only "drain artificial energy," 44 whereas "natural energy from the great outdoors" defeats them. ${ }^{45}$ To fight the aliens, Astro Boy and the other remaining robots band together to form a single, bigger robot-in doing so, they directly imitate the strategies of the alien life form that bands together in "colonies" to form its shape-shifting manifestations. ${ }^{46}$ In the shape of a mega-robot, the robots absorb a lightning strike (natural energy) and direct it against the aliens, who promptly flee back into space.

The story was generally organized in a construction that Tezuka often used in his plots. He foregrounds an individual, personal drama of loss - in this case, Astro Boy finds his parents lifeless on the floor of their living room. ${ }^{47}$ This individual drama is then related to larger structural issues - in this case, the twin challenge of invasion and pollution. Just like how Superman alone absorbs radiation, Astro Boy absorbs mourning and, at the same time, focuses the story on the theme of pollution rather than invasion; the invasion is only important insofar as it offers Astro Boy a strategy to undo his representative mourning and "repair" his parents. ${ }^{48}$

This construction is especially important in this story because the notion of invasion has unmistakable political subtexts for postwar Japanese audiences. When the snow falls and does its destructive work, the parallel to nuclear attacks and radiation poisoning is rather obvious. Even the distinction between "natural" and "artificial" energy embodies the theme of ionizing radiation: many scientific introductions to the topic start by emphasizing not only that the sources of ionizing radiation can be

\footnotetext{
${ }^{38}$ Schodt, Astro Boy Essays, 19-20.

${ }^{39}$ See, e.g., Tezuka, "Space Snow Leopard," 258.

${ }^{40}$ Schodt, Astro Boy Essays, 125.

${ }^{41}$ See Curtis, "Superheroes and the Mythic Imagination."

42 Tranter, "Doing Right in the World," 102.

${ }^{43}$ Tezuka, "Space Snow Leopard," 267.

${ }^{44}$ Tezuka, "Space Snow Leopard," 283.

45 Tezuka, "Space Snow Leopard," 294.

46 Tezuka, "Space Snow Leopard," 279.

${ }^{47}$ Tezuka, "Space Snow Leopard," 250.

48 Tezuka, "Space Snow Leopard," 278.
} 
"both natural and artificial (man made)"49 but also that artificial radiation tends to be more dangerous because it is more concentrated than natural radiation. In "Space Snow Leopard," the weather itself becomes a weapon of attack. The snow is reminiscent of black rain, and it drains the life energy of those affected, being a much-sanitized version of acute radiation poisoning in which the body unsuccessfully tries to fight off its own disintegration.

If ionizing radiation is so clearly evoked, the political parallel to the historical experience of Hiroshima and Nagasaki are almost impossible to avoid in a plot about an alien invasion. The alien attack in "Space Snow Leopard" comes from the sky without warning or provocation, the central humanoid antagonist presents as a scientist, and the aliens' objectives are invasion and occupation. Nothing would be easier than to read this as an anti-American political parable that casts the United States as an alien aggressor and Japan as a wrongfully assaulted, peaceful neighbor.

However, Tezuka was not the writer to go down that path. He belonged to a generation of artists who came of age in Americanoccupied Japan and who favored integration over opposition, and he was generally greatly influenced by American aesthetic models. More importantly, as Tezuka's consistent treatment of structural discrimination against robots in Astro Boy indicated, the one political parable he did develop consistently and deliberately in the series was not one of a good community triumphing over an evil one but one of all life having equal rights to live and to act in the world (e.g., robots and humans). The premise of "Space Snow Leopard" threatened to mobilize a political parable Tezuka actually sought to avoid (i.e., the United States as evil aggressors) while undermining the political parable he actually wanted to establish throughout the series (i.e., the kinship of all life, including humans, robots, and, in this case, even aliens).

Tezuka's response to this impressively difficult problem of storytelling was to evoke a kinship between all the realms, a kinship that underlay everything in the plot of "Space Snow Leopard" and that was most centrally established in the images. For example, the aliens' kinship with robots was established through a shared diversity of visual manifestation (i.e., both robots and aliens came in humanoid and non-humanoid forms and could band together to form entirely new manifestations). At the same time, the representation of aliens went far beyond this. The aliens took the forms of humans, animals, slime, and even weather phenomena-in other words, alien life was presented as an integrated environment of multiple species and environmental factors that mirrors the integrity of life forms "natural" to earth.

This notion of universal kinship across the realms was substantiated by consistent usage of visual metaphor. For example, the aliens' shape-shifting versatility was marked by the prevalence of hollow circles on the page. The hollow circles connected the representation of snowflakes, leopard dots, the mad scientist's pupil-less eyes, and even the computer paper that the aliens used ${ }^{50}$ Intriguingly, the metaphor of the circle did its integrative work even when it was discontinued. For example, the mad scientist's eyes lost their characteristic hollowness in direct confrontations with humans, thus pointedly removing any overt visual reminder of the scientist's Otherness in situations of violent struggle..$^{51}$

Yet this unifying visual metaphor of alien life was not exclusively applied to alien shapes. It extended to examples of life forms on earth and appeared in pictures of amoebae, corals, and jellyfish. ${ }^{52}$ Indeed, the aliens' organic and organizational kinship with these terrestrial, colony-forming life forms gave Astro Boy the idea to form the mega-robot. It is the relationality of all life that is key to the story's resolution.

There is something like an essentialist divide in the story, and it runs between "natural" versus "artificial" energy and the entities powered by them. This divide elegantly renders it plausible for humans not to be affected by the snow at all. Happily, in this alternative universe, there is no disintegrating radiation sickness in "natural" beings; there are only "artificial" robots that temporarily break down. Humans count as "natural" rather than as "artificial" beings. Their life energy cannot be drained on general principle; in contrast, the robots' reliance on artificial energy is used as their Achilles heel like kryptonite in Superman. While this could already be summarized as the gratifying fantasy that "Space Snow Leopard" revolves around (i.e., not "we as humans can control pollution" but "we as humans are inherently not affected by it"), the natural-artificial distinction is not quite as neat as that.

"Artificial" in this story has an entirely different function from that in either classic examples of the human-nature divide (where artificiality can be translated as "being available as property") or the related context of radiation literature (where artificiality signals greater harm to the body). Tezuka mobilizes the divide to formulate a clearly perceptible fantasy of immunity in a way that does not seal off humans' bodies from the world they inherit, inhabit, and shape. In casting humans as "natural"

\footnotetext{
${ }^{49}$ Gupta, Environmental Pollution, 159.

50 Tezuka, "Space Snow Leopard," 247, 250, 264, 265, 280, 283.

${ }^{51}$ E.g., Tezuka, "Space Snow Leopard," 284.

52 Tezuka, "Space Snow Leopard," 267, 279.
} 
to save his characters from irreparable harm, Tezuka evoked the same equivalence between humans and their non-human environment that Kate Brown noted in her description of the May holiday in Kyiv-but in Tezuka's case, trees and Kyvians are not collectively affected but collectively immune.

Intriguingly, the divide is not a problem of essentialism to be overcome in the story, but it is actively put in the service of what Tranter calls Tezuka's "vision of being: being as living and making choices, and not the unfolding of essential characteristics." 53 In this spirit, the divide in "Space Snow Leopard" achieves two core things. First, it robustly connects human life with all other planetary life. Second, it renders the classic human-nature divide's central understanding of absorption being consumption as an inherently harmful and hostile practice. After all, artificial energy gives power to ("feeds") both robots and aliens, and it is precisely through the story's focus on pollution that the deciding factor becomes absorption (just as it arguably does in a Lockean understanding of property). The entire invasion is about energy absorption - the mourned robot parents are not collateral damage but the intended target.

The one life form that absorbs other life forms as resources to be harvested in the colonialist tradition of property absorption is the one whose removal concludes the story. This happy ending can be unequivocal because it resonates with a larger, structurally dichotomist science fiction trope of driving hostile aliens with voracious appetites back into space. ${ }^{54}$ But in this case, the aliens are not cast as inherently different just because they are predatory. Their social organization can be recognized as familiar and imitated by the robots in the spirit of cooperation; the aliens' relationship with each other (e.g., the relationship between scientist and leopard) can be recognized as caring.

In the case of these particular aliens, it is not their nature as inherently "different" beings that is rejected but their interpretation and management of absorption specifically (and thus their vision of legal and political rule). This integration of the aliens into the kinship of life while simultaneously rejecting their predatory absorption of energy as property (in its original double sense) is ultimately the move that disables the possibility of using property as an axis to relate human and nature in this story. Tezuka's widely acknowledged rejection of structural discrimination finds its necessary logical flipside here: the equally persistent rejection of presenting imperialists as Vitruvian clichés.

It should be cautioned that the robots' defeat of the aliens is by far the weakest part of the plot. In "Space Snow Leopard," winning the battle is conveniently equivalent to winning the war, which is neither an integral part of the story-motivating fantasy of immunity nor a particularly insightful element of political parable. Yet even though Tezuka sidesteps the issue of imperial persistence, the story achieves something impressive. Rather than offering a crude straw figure of a monster of the week, the story not only deftly isolates "artificial" metaphors of property being absorption as the alien force that slithers out of the picture but also makes room for a triumphant view on the human being as self-evidently integrated within the wealth of life-across the species and even across further limitations, such as the equation of life with organic life.

\section{Conclusion}

As Tezuka's example indicates, the substantive critique of institutional premises is not only possible from within institutional contexts but also able to become enduringly successful within these contexts (e.g., of publishing and critique). Thanks to the versatile formal interplay between text and image, Tezuka's Astro Boy may constitute one compositional model among many to work toward an approach of philosophical and political speech that systematically regroups categorical language around images that confound us - the mushroom cloud, the burning forest, the melting iceberg.

Especially in the age of the Internet (not to mention political mobilization via the Internet), there is no real need to stick with straw figures and counterpositions to formulate a challenge to property-based human exceptionalism. In the face of our existing cultural embrace of an ever-greater range of image-text compositions, it might be worthwhile to recognize the potential of comics as a genre with a long history of negotiating the issue of pollution, specifically in the interplay of word and image.

The dichotomist view argues that our distinct privilege as humans is a power of absorption and that we can absorb everything through property. But as we have seen, popular texts like "Space Snow Leopard" exist in which the human-nature divide has already ceased to motivate a fantasy of overcoming catastrophe. "Space Snow Leopard" exemplifies a kind of text that does

\footnotetext{
53 Tranter, "Doing Right in the World," 101.

${ }^{54}$ The arc of this structure goes back to the early modern Barbary Captivity Narrative in Western storytelling. The original setting of the Mediterranean motivated the idea of a confrontation with a unified, hostile Other that perpetually lurks at sea. Schillings, Enemies of All Humankind, 69-81. In science fiction, the notion of the techno-organic hybrid is often framed in this tradition (e.g., in Star Trek [the Borg] or Doctor Who [the Cybermen]).
} 
not only articulate an alternative categorical premise coherently but also sidesteps the structural traps that the CSC and Braidotti's Vitruvian Man exemplified.

In Tezuka's story, "the divide" is a structural citation that both facilitates legibility (because it roots the story in the familiar) and assists the story in formulating its radical idea of a nature that includes the human. The strength of this move is shown by its implications. Contemporary catastrophes make social conflict contingent on factors such as weather, soil, or non-human life forms, such as viruses. How should we, for example, make sense of the profound societal reckoning following George Floyd's killing by police without considering the Covid-19 pandemic that especially ravages BIPOC communities in the United States? "Space Snow Leopard" indicates that it is absolutely possible to address both an existential social issue and an existential exposure to "nature" without one issue diminishing or displacing the other.

Comics like these, through their very form, revise the theme of absorption in its function as a foundation of the human condition within the world. In the tension between what the text says and what the image shows, we can start thinking about philosophy, the law, and, ultimately, politics differently because they give us strategies to think of pollution differently. Comics like these use the tension between fantasy and catastrophe as a methodical starting point for a fundamental rewriting of institutional paradigms. We might be able to use comics — an intuitive predecessor for Internet communication in particular - to formulate positions that may even result in institutional reforms that are as consequential and enduring as the human rights regime was at the dawn of the atomic age. These comics issue an invitation. Instead of dropping cyanide pills, we might consider taking them up on it.

\section{Bibliography}

Boyer, Paul. By the Bomb's Early Light: American Thought and Culture at the Dawn of the Atomic Age. Chapel Hill: University of North Carolina Press, 1994.

Braidotti, Rosi. The Posthuman. Cambridge: Polity Press, 2013.

Brown, Kate. Manual for Survival: A Chernobyl Guide to the Future. London: Allen Lane, 2019.

Curtis, Neal. "Superheroes and the Mythic Imagination: Order, Agency and Politics." Journal of Graphic Novels and Comics (November 2019): 1-15. https://dx.doi.org/10.1080/21504857.2019.1690015

Convention on Supplementary Compensation for Nuclear Damage. Arg.-Can.-Ghana-India-Japan-Moroc.-MontenegroRoma.-U.A.E.-U.S. July 22, 1998. INFCIRC/567. https://www.iaea.org/sites/default/files/infcirc567.pdf

Düwell, Marcus, Jens Braarvig, Roger Brownsword and Dietmar Mieth, eds. The Cambridge Handbook of Human Dignity: Interdisciplinary Perspectives. Cambridge: Cambridge University Press, 2014.

Esposito, Roberto. Person und menschliches Leben. Zürich and Berlin: diaphanes, 2010.

Fisch, Jörg. Die europäische Expansion und das Völkerrecht: Die Auseinandersetzungen um den Status der überseeischen Gebiete vom 15. Jahrhundert bis zur Gegenwart. Stuttgart: Steiner, 1984.

Geldon, Mary Ann. A World Made New: Eleanor Roosevelt and the Universal Declaration of Human Rights. New York: Random House Trade Paperbacks, 2002.

Giaimo, Cara. "The Long, Weird Half-Life of Trinitite.” Atlas Obscura, June 30, 2017. https://www.atlasobscura.com/articles/trinitite-trinity-test-mineral-cultural-jewelry

Gilbert, Scott F., Jan Sapp and Albert I. Tauber. “A Symbiotic Way of Life: We Have Never Been Individuals.” The Quarterly Review of Biology 87, no 4 (2012): 325-41. https://doi.org/10.1086/668166

Griffiths, David. "Queer Theory for Lichens.” UnderCurrents 19 (2015): 36-45.

Guleria, Ravider, Brijender Bhushan, Ankit Guleria, Ajay Bhushan and Pawitar Dulari. "Harmful Effects of Ionizing Radiation.” International Journal for Research in Applied Science \& Engineering Technology 7, no 12 (2019): 887-89.

Gupta, R. D. Environmental Pollution: Hazards and Control. New Delhi: Concept Publishing, 2006.

Hammontree, D. R. “Adventure Comics.” In Comics through Time: A History of Icons, Idols, and Ideas. Vol. III, edited by Keith Booker, 449-51. Santa Barbara: ACO-CLIO, 2014.

Harrison, Kevin and Tony Boyd. Understanding Political Ideas and Movements. Manchester: Manchester University Press, 2003.

Heffron, Raphael J. and William J. Nuttall. “The Global Nuclear Liability Regime Post Fukushima Daiichi.” Progress in Nuclear Energy 90 (July 2016): 1-10. https://doi.org/10.1016/j.pnucene.2016.02.019

Jacobs, Robert. "Nuclear Conquistadors: Military Colonialism in Nuclear Test Site Selection during the Cold War." Asian Journal of Peacebuilding 1, no 2 (2013): $157-77$. 
Jennings, Jackson S. “Superman.” In Comics through Time: A History of Icons, Idols, and Ideas. Vol. III, edited by Keith Booker, 799-803. Santa Barbara: ACO-CLIO, 2014.

Kant, Immanuel. "Perpetual Peace: A Philosophical Sketch.” Mount Holyoke College. 1795. https://www.mtholyoke.edu/acad/intrel/kant/kant1.htm

Krupar, Shiloh R. Hot Spotter's Report: Military Fables of Toxic Waste. Minneapolis: University of Minnesota Press, 2013.

Kuri, Visa. "Animals, Slaves, and Corporations: Analyzing Legal Thinghood.” German Law Review 18, no 5 (2017): 106990. https://doi.org/10.1017/s2071832200022252

Langton, Rae. "What's the Point of Immortality? (Annual Lecture, 2017)." YouTube Video, 55:26. Posted March $31,2017$. https://m.youtube.com/watch?v=Ov17tbcqbHs

Lavery, Danny M. "Dear Prudence: My White Girlfriend Told My Black Mom that Eating Vegan Is Like the Civil Rights Movement.” Slate, April 9, 2020. https://slate.com/human-interest/2020/04/dear-prudence-white-girlfriend-vegan-civilrights-movement-black-mom.html

Locke, John. "The Second Treatise of Government: An Essay Concerning the True Original, Extent, and End of Civil Government." In Two Treatises of Government, edited by Peter Laslett, 270-400. Cambridge: Cambridge University Press, 1988.

McCrudden, Christopher, ed. Understanding Human Dignity. Oxford: Oxford University Press, 2014.

Mills, Charles W. "Racial Liberalism.” PMLA 123, no 5 (2008): 1380-97.

Olson, Greta. Criminals as Animals from Shakespeare to Lombroso. Berlin: DeGruyter, 2014.

Poth, Chlodwig, ed. "Jörg, der Effekthascher." In Das Katastrophenbuch: 24 Bildgeschichten [The Disaster Book: 24 Picture Stories], 152-57. My translation. Hamburg: Hoffmann \& Campe, 1982.

Rhoades, Shirrel. A Complete History of American Comic Books. New York: Lang, 2008.

Schillings, Sonja. Enemies of All Humankind: Fictions of Legitimate Violence. Hanover: University Press of New England, 2017.

Schodt, Frederik L. The Astro Boy Essays: Osamu Tezuka, Mighty Atom, Manga/Anime Revolution. Berkeley: Stone Bridge Press, 2007.

Tezuka, Osamu. “A Day to Remember.” In Astro Boy Omnibus 2, 55-69. Translated by Frederick L. Schodt. Milwaukie: Dark Horse Manga, 2015.

Tezuka, Osamu. “Crucifix Island.” In Astro Boy Omnibus 2, 157-244. Translated by Frederick L. Schodt. Milwaukie: Dark Horse Manga, 2015.

Tezuka, Osamu. "Space Snow Leopard." In Astro Boy Omnibus 2, 245-98. Translated by Frederick L. Schodt. Milwaukie: Dark Horse Manga, 2015.

Tranter, Kieran. "Doing Right in the World with 100,000 Horsepower: Osamu Tezuka's Tetsuwan Atomu (Astro Boy), Essence, Posthumanity and Techno-Humanism." In Law and Justice in Japanese Popular Culture: From Crime Fighting Robots to Dueling Pocket Monsters, edited by Ashley T. Pearson, Thomas Giddens and Kieran Tranter, 95-111. London: Routledge, 2018.

UN General Assembly. Universal Declaration of Human Rights. December 10, 1948. https://www.un.org/en/universaldeclaration-human-rights/index.html

Washburn, Wilcomb E. Red Man's Land, White Man's Law. 2nd ed. Norman: University of Oklahoma Press, 1995.

Wetz, Franz Josef. Texte zur Menschenwürde. Stuttgart: Reclam, 2011.

Wormouth, Francis D. and Edwin B. Firmage. To Chain the Dog of War: The War Power of Congress in History and Law. 2nd ed. Urbana: University of Illinois Press, 1989. 